Indo. J. Chem. Res., 2017, 5(1), 1-6

\title{
PENGARUH VARIASI GARAM AMMONIUM TERHADAP KEASAMAN ZEOLIT ALAM PADA REAKSI PERENGKAHAN MINYAK JELANTAH
}

\author{
The Effect of Ammonium Salt Variation on Natural Zeolite Acidity in Catalytic \\ Cracking of Waste Cooking Oil
}

\author{
Verry Andre Fabiani ${ }^{1 *}$, Imelda H. Silalahi ${ }^{2}$, Endah Sayekti ${ }^{2}$ \\ ${ }^{I}$ Department of Chemistry, Faculty of Engineering, Bangka Belitung University \\ Jl.Kampus Peradaban Bangka 33172, Balunijuk, Bangka-Indonesia \\ ${ }^{2}$ Department of Chemistry, Faculty of Mathematics and Natural Sciences, Tanjungpura University \\ Jl. Prof.Dr. Hadari Nawawi, Pontianak-Indonesia \\ *Corresponding author, e-mail: verry-andre@ubb.ac.id
}

Received: Dec. 2016 Published: July 2017

\begin{abstract}
Natural zeolite modification with the addition of ammonium salt variations was conducted. The modification was conducted by demineralization method, dealumination and followed by activation of ammonium salt. The types of activators were ammonium chloride, ammonium nitrate and ammonium fluoride. The effect of ammonium salt was assessed through acidity parameter with $\mathrm{Si} / \mathrm{Al}$ ratio variable and applied catalyst for catalytic cracking of waste cooking oil. The results showed that the activation of natural zeolite by using ammonium chloride salt could increase the acidity of natural zeolite with the highest $\mathrm{Si} / \mathrm{Al}$ ratio about 15.56. Based on the XRF analysis showed that the reduced amount of Na metal in zeolite about $92.8 \%$. The effect of ammonium salt variation on the acidity of natural zeolites was observed by applying a catalyst in the catalytic cracking of waste cooking oil. Physical characteristic of catalytic cracking products from waste cooking oil indicated all products fulfill the solar standards requirement. The results concluded that ammonium chloride salt was the best activator in natural zeolite modification and generally all ammonium salts gave high acidity effect to natural zeolite in catalytic cracking of waste cooking oil.
\end{abstract}

Keywords: Ammonium salt, acidity, cracking, waste cooking oil, natural zeolite

\section{PENDAHULUAN}

Zeolit umumnya dimanfaatkan sebagai katalis pada industri kimia dan sebagai zat pengemban. Zeolit merupakan kristal alumina silika yang mempunyai struktur berongga atau pori yang mempunyai sisi aktif dengan rasio $\mathrm{Si} / \mathrm{Al}$ yang cukup tinggi dan bersifat selektif sehingga sangat baik digunakan dalam reaksi perengkahan. Bentuk kristal zeolit relatif teratur dengan rongga yang saling berhubungan ke segala arah menyebabkan permukaan zeolit menjadi sangat luas dan baik bila digunakan sebagai adsorben (Tarach et al., 2014). Umumnya zeolit yang ditambang langsung dari alam masih mengandung pengotor-pengotor organik dan anorganik yang menutupi porinya, sehingga untuk meningkatkan kemampuan daya serap zeolit alam harus dilakukan aktivasi terlebih dahulu.
Pemakaian zeolit sebagai katalis telah banyak digunakan, diantaranya sebagai katalis dalam perengkahan minyak goreng bekas (Li et al., 2015) dan katalis dalam proses konversi etanol menjadi hidrokarbon (Ramasamy et al., 2014). Kapasitas zeolit sebagai katalis perengkahan didasarkan pada tingkat keasaman dan kestabilan material yang terlihat dari rasio Si/Al. Keasaman yang tinggi dapat meningkatkan aktivitas katalitik dan stabilitas termal serta ketahanan terhadap asam. Inti aktif katalis zeolit yang berfungsi dalam reaksi perengkahan adalah bagian asam Bronsted yang berpusat pada atom Al (Song et al, 2013 ; Park et al., 2017). Situs asam dalam kerangka zeolit ada dua jenis yaitu situs asam Brønsted dan situs asam Lewis. Modifikasi untuk meningkatkan keasaman dilakukan terhadap zeolit alam dengan aktivasi melalui proses pertukaran ion dengan ion ammonium, dilanjutkan dekomposisi panas 


\section{Verry Andre Fabiani dkk./ Indo. J. Chem. Res., 2017, 5(1), 1-6}

dari bentuk pertukaran amoniumnya sehingga diperoleh situs asam Brønsted (Tatsumi, 2004).

Reaksi perengkahan (catalytic cracking) merupakan suatu reaksi katalisis untuk memecah hidrokarbon kompleks menjadi molekul yang lebih sederhana. Penelitian ini berfokus pada kajian pengaruh garam ammonium dalam aktivasi zeolit alam. Kombinasi dari peningkatan keasaman dan kestabilan termal zeolit alam merupakan parameter keberhasilan suatu reaksi katalitik perengkahan. Pada penelitian ini dilakukan modifikasi zeolit alam dengan aktivator berupa jenis senyawa amonium yaitu amonium klorida $\left(\mathrm{NH}_{4} \mathrm{Cl}\right)$, amonium nitrat $\left(\mathrm{NH}_{4} \mathrm{NO}_{3}\right)$, dan amonium florida $\left(\mathrm{NH}_{4} \mathrm{~F}\right)$. Pertukaran ion amonium dengan ion $\mathrm{Na}^{+}$pada zeolit akan menambah situs-situs asam pada zeolit sehingga keasaman pada zeolit akan meningkat. Hasil aktivasi ini diharapkan dapat meningkatkan keasaman bersamaan dengan peningkatan rasio $\mathrm{Si} / \mathrm{Al}$. Selanjutnya akan ditentukan jenis katalis zeolit teraktivasi terbaik yang diperoleh melalui analisis produk reaksi perengkahan minyak jelantah yang dihasilkan.

\section{METODOLOGI}

\section{Bahan}

Akuades, minyak jelantah, zeolit alam asal Bandung Selatan-Jawa Barat dan bahan kimia Merck yaitu $\mathrm{NH}_{4} \mathrm{~F} 1 \mathrm{M}, \mathrm{NH}_{4} \mathrm{Cl} 1 \mathrm{M}, \mathrm{NH}_{4} \mathrm{NO}_{3} 1$ $\mathrm{M}, \mathrm{HNO}_{3} 8 \mathrm{M}, \mathrm{Na}_{2} \mathrm{EDTA}, \mathrm{NaOH}$.

\footnotetext{
Alat

Neraca analitik merk Ohaus, oven merk Memmert, $\mathrm{pH}$ universal, piknometer merk Pyrex tipe 26, 28, 34, seperangkat alat destilasi, seperangkat alat gelas standar merk Pyrex, seperangkat alat refluks, furnace merk Nabertherm mode L3, viskometer otswald merk Pyrex tipe 300, X-Ray Fluoroscence (XRF) tipe ADVANT XP Thermo ARL.

\section{Prosedur Kerja Preparasi Sampel}

Sampel dicuci dengan akuades hingga mencapai $\mathrm{pH}$ pencuci. Dikeringkan di oven hingga kering pada suhu $110{ }^{\circ} \mathrm{C}$ selama 4 jam. Sampel yang telah kering kemudian ditimbang. Sampel kemudian dianalisis dengan X-Ray Fluoroscence (XRF) (Silalahi, dkk., 2011).
}

\section{Demineralisasi dengan EDTA $1 \mathrm{M}$}

Sampel hasil pencucian kemudian dicuci kembali dengan larutan EDTA 1M. Pencucian dilakukan dengan proses refluks pada suhu $80{ }^{\circ} \mathrm{C}$ selama 24 jam. Setelah proses refluks selesai, sampel kemudian dicuci dengan akuades hingga mencapai $\mathrm{pH}$ pencuci $(\mathrm{pH}=6)$. Dikeringkan di oven pada suhu $110{ }^{\circ} \mathrm{C}$ selama 4 jam, setelah kering kemudian sampel ditimbang untuk proses berikutnya. Sampel hasil pencucian EDTA ini dianalisis dengan X-Ray Fluoroscence (XRF) (Silalahi dkk., 2011).

\section{Dealuminasi dengan $\mathrm{HNO}_{3}$}

Sampel yang telah dicuci dengan EDTA 1M kemudian dileaching dengan $\mathrm{HNO}_{3} 8 \mathrm{M}$. Proses ini juga merupakan proses dealuminasi terhadap sampel zeolit. Sampel zeolit ditimbang dan kemudian direfluks pada suhu $80{ }^{\circ} \mathrm{C}$ selama 24 jam. Setelah proses refluks selesai, sampel kemudian dicuci dengan akuades hingga mencapai $\mathrm{pH}$ pencuci $(\mathrm{pH}=6)$. Dikeringkan di oven pada suhu $110{ }^{\circ} \mathrm{C}$ selama 4 jam, setelah kering kemudian sampel ditimbang untuk proses berikutnya (Silalahi dkk., 2011).

\section{Aktivasi dengan Variasi Garam Ammonium $\left(\mathrm{NH}_{4} \mathbf{Y}\right)$}

Sampel hasil dealuminasi kemudian diaktivasi dengan $\mathrm{NH}_{4} \mathrm{Y}$. Pada penelitian ini digunakan aktivator jenis senyawa amonium yaitu amonium klorida $\left(\mathrm{NH}_{4} \mathrm{Cl}\right)$, amonium nitrat $\left(\mathrm{NH}_{4} \mathrm{NO}_{3}\right)$ dan amonium florida $\left(\mathrm{NH}_{4} \mathrm{~F}\right)$. Tiaptiap senyawa amonium ini dibuat dengan konsentrasi $1 \mathrm{M}$ kemudian direfluks masingmasing dengan sampel pada suhu $80{ }^{\circ} \mathrm{C}$ selama 24 jam. Setelah proses refluks selesai, ketiga sampel hasil aktivasi kemudian dicuci dengan akuades hingga mencapai $\mathrm{pH}$ pencuci $(\mathrm{pH}=6)$. Dikeringkan di oven pada suhu $110{ }^{\circ} \mathrm{C}$ selama 4 jam, setelah kering kemudian sampel ditimbang untuk proses berikutnya. Sampel hasil aktivasi dianalisis dengan $X$-Ray Fluoroscence (XRF).

\section{Kalsinasi Sampel}

Zeolit hasil aktivasi kemudian dikalsinasi pada suhu $500{ }^{\circ} \mathrm{C}$ di dalam furnace selama 2 jam. Katalis hasil kalsinasi ini kemudian dianalisis dengan X-Ray Fluoroscence (XRF) (Silalahi, dkk., 2011). 


\section{Verry Andre Fabiani dkk./ Indo. J. Chem. Res., 2017, 5(1), 1-6}

\section{Proses Perengkahan Katalitik}

Minyak jelantah sebanyak $40 \mathrm{~g}$ bersama dengan zeolit sebanyak $10 \mathrm{~g}$ dicampurkan dalam suatu labu destilasi selanjutnya dipanaskan pada temperatur $350-360{ }^{\circ} \mathrm{C}$ dalam labu destilasi yang telah dihubungkan dengan kondensor. Uap minyak jelantah yang telah direngkahkan oleh zeolit kemudian didinginkan melewati kondensor, sehingga uap tersebut terkondensasi. Reaksi dihentikan ketika komposisi minyak dalam labu pemanas sudah habis atau sudah tidak mengeluarkan uap cair. Produk perengkahan kemudian dikarakterisasi sifat fisik dan kimianya yang meliputi indeks bias, densitas, viskositas kinematik, dan uji nyala api (Silalahi, dkk., 2011).

\section{HASIL DAN PEMBAHASAN}

\section{Modifikasi Zeolit Alam dan Karakterisasi Zeolit Termodifikasi}

Modifikasi zeolit alam meliputi beberapa tahapan yaitu demineralisasi, dealuminasi, aktivasi dengan variasi garam amonium dan kalsinasi. Tahapan pertama yaitu dilakukan proses demineralisasi zeolit alam dengan larutan Etilen Diamin Tetra Asetat (EDTA). Tujuan demineralisasi ini untuk menghilangkan logamlogam pengotor yang berada pada fasa permukaan struktur zeolit. Pada dasarnya EDTA merupakan ligan kuat yang dapat berikatan dengan logam logam membentuk senyawa kompleks. EDTA sebenarnya adalah ligan seksidentat yang dapat berkoordinasi dengan suatu ion logam lewat kedua nitrogen dan keempat gugus karboksil-nya atau disebut ligan multidentat yang mengandung lebih dari dua atom koordinasi per molekul, misalnya asam 1,2diaminoetanatetraasetat (asametilenadiamina tetraasetat, EDTA) yang mempunyai dua atom nitrogen penyumbang dan empat atom oksigen penyumbang dalam molekul (Rival, 1995). Perlakuan sampel dengan larutan Etilen Diamin Tetra Asetat (EDTA) juga dilakukan untuk mengetahui penyebaran logam-logam yang diembankan pada bagian luar permukaan dan dalam rongga pengemban serta dapat menghilangkan fasa amorf non framework sehingga kristal yang diperoleh lebih murni (Triwahyuni, 2003).

Perlakuan sampel dengan larutan Etilen Diamin Tetra Asetat (EDTA) juga dilakukan untuk mengetahui penyebaran logam-logam yang diembankan pada bagian luar permukaan dan dalam rongga pengemban serta dapat menghilangkan fasa amorf non framework sehingga kristal yang diperoleh lebih murni (Triwahyuni, 2003). Perlakuan selanjutnya yaitu dealuminasi zeolit dengan menambahkan larutan $\mathrm{HNO}_{3}$ 8M. Menurut Handhoyo, dkk., (2005) konsentrasi optimal untuk dealuminasi zeolit dilakukan dengan menggunakan $\mathrm{HNO}_{3} 8 \mathrm{M}$. Peningkatan konsentrasi asam dapat meningkatkan intensitas serangan proton $\mathrm{H}^{+}$ (Ismail dan Hanudin, 2005). Penyerangan proton terjadi karena ukurannya yang kecil $(\mathrm{r}=0,3 \mathrm{~A})$ dan potensial ionnya $(\mathrm{q} / \mathrm{r})$ yang besar sehingga ion $\mathrm{H}^{+}$dapat masuk ke dalam kisi-kisi mineral dan menggantikan posisi kation yang lepas.

Dealuminasi digunakan untuk proses penghilangan logam aluminium pada suatu zeolit dengan menggunakan larutan asam (Xu, et al., 2014). Tujuan dari proses dealuminasi zeolit ini adalah untuk meningkatkan keasaman dari suatu katalis zeolit dan dapat meningkatkan efisiensi dari katalis itu sendiri (Muller, et al., 2014). Dealuminasi dapat ditunjukkan melalui peningkatan rasio Si/Al. Proses dealuminasi merupakan suatu metode untuk menjaga stabilitas struktur pori dan menghilangkan alumina dari framework zeolit agar katalis ini tidak mudah mengalami deaktivasi. Proses dealuminasi biasanya dilakukan dengan menambah sejumlah asam (misalnya amonium klorida, asam klorida, asam florida, dan sebagainya) pada zeolit (Jestyssa, 2010).

Pada dealuminasi, ion $\mathrm{H}^{+}$yang dihasilkan dari reaksi penguraian $\mathrm{HNO}_{3}$ dalam medium air akan mengurai ikatan atom $\mathrm{Al}$ yang berada pada framework zeolit. Ion $\mathrm{H}^{+}$ini akan diserang oleh atom oksigen yang terikat pada $\mathrm{Si}$ dan $\mathrm{Al}$. Berdasarkan harga energi disosiasi ikatan Al-O (116 kkal/mol) jauh lebih rendah dibandingkan energi disosiasi ikatan Si-O (190 kkal/mol), maka ikatan Al-O jauh lebih mudah terurai dibandingkan Si-O. Sehingga ion $\mathrm{H}^{+}$akan cenderung menyebabkan terjadinya pemutusan ikatan Al-O dan akan terbentuk gugus silanol. Sedangkan ion $\mathrm{NO}_{3}{ }^{-}$hasil penguraian ion $\mathrm{HNO}_{3}$ juga akan mempengaruhi kekuatan ikatan Al-O dan Si-O. Ion $\mathrm{NO}_{3}{ }^{-}$memiliki elektronegativitas yang tinggi dan berukuran kecil, sehingga menyebabkan ion ini mudah berikatan dengan kation bervalensi besar seperti $\mathrm{Si}^{4+}$ dan $\mathrm{Al}^{3+}$. Tetapi ion $\mathrm{NO}_{3}^{-}$akan cenderung berikatan dengan atom $\mathrm{Al}$ dikarenakan harga 


\section{Verry Andre Fabiani dkk./ Indo. J. Chem. Res., 2017, 5(1), 1-6}

elektronegativitas atom $\mathrm{Al}$ lebih kecil $(1,61)$ dibanding elektronegativitas atom $\mathrm{Si}(1,90)$.

Aktivasi selanjutnya dilakukan dengan garam amonium, pemilihan variasi garam amonium yaitu amonium klorida, amonium nitrat dan amonium florida bertujuan untuk mengetahui jenis garam amonium yang dapat meningkatkan rasio Si/Al pada zeolit. Umumnya zeolit digunakan sebagai katalis terutama dalam reaksi transformasi hidrokarbon dengan memanfaatkan keasamaannya. Dalam suatu reaksi, fungsi zeolit adalah membantu pembentukan ion karbonium oleh situs-situs asam yang ada pada zeolit tersebut. Selain itu situs-situs basa dan proses radikal bebas juga dilibatkan dalam suatu reaksi. Adanya hidroksi dalam saluran zeolit, memungkinkan pembentukan situs asam Bronsted yang merupakan donor proton. Mekanisme pertukaran ion pada permukaan zeolit (Gambar 1) terjadi melalui penukaran kation dengan ion ammonium yang kemudian dipanaskan agar $\mathrm{NH}_{3}$ yang tersisa dapat diuapkan. (Saiapina et al., 2012) :

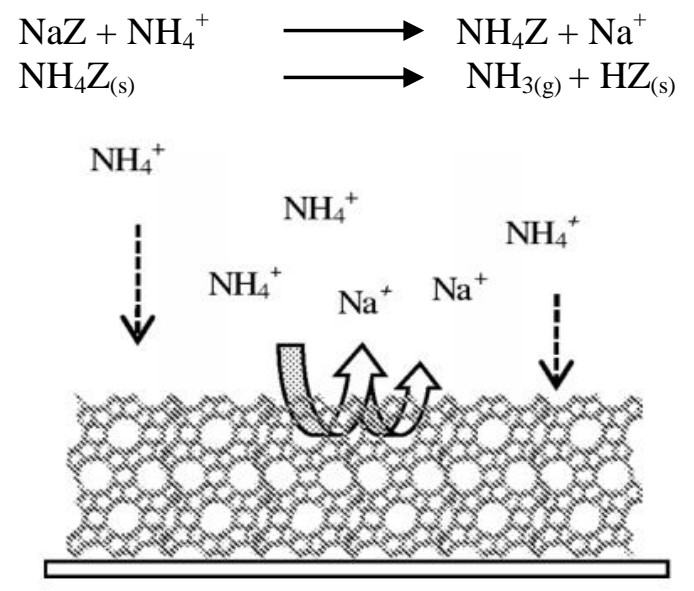

Gambar 1. Mekanisme pertukaran ion pada permukaan zeolit

Modifikasi untuk meningkatkan keasaman dilakukan terhadap zeolit alam dengan aktivasi melalui proses pertukaran ion dengan ion ammonium, dilanjutkan dekomposisi panas dari bentuk pertukaran amoniumnya sehingga diperoleh situs asam Brønsted (Tatsumi, 2004).

Ion hidrogen yang terbentuk akan membentuk gugus hidroksil dengan tetrahedral $\mathrm{AlO}^{-}$yang pada temperatur $>200{ }^{\circ} \mathrm{C}$ bergerak bebas diantara pusat-pusat aktif. Bila temperatur mencapai $500{ }^{\circ} \mathrm{C}$, inti asam Bronsted tersebut membentuk situs asam Lewis. Oleh sebab itu pada penelitian ini dilakukan kalsinasi pada suhu $500{ }^{\circ} \mathrm{C}$ yang bertujuan untuk menguapkan basa Lewis selain itu proses kalsinasi ini dilakukan untuk menjaga agar katalis yang diperoleh relatif stabil pada suhu tinggi dan dapat mengatur kembali tata letak atom yang tertukar agar lebih teratur (Jestyssa, 2010).

\section{Analisis Komposisi Kimia}

Komponen kimia yang terkandung berpengaruh terhadap karakteristik zeolit. Pada umumnya mineral zeolit mengandung silika dan alumina serta sejumlah kecil kation logam. Penentuan kandungan silika dan alumina menjadi parameter awal keberhasilan dalam proses aktivasi zeolit alam.

Tabel 1. Komposisi kimia zeolit alam dan zeolit $\mathrm{NH}_{4} \mathrm{Y}$

\begin{tabular}{crrrr}
\hline \multirow{2}{*}{$(\%)$} & \multicolumn{4}{c}{ Sampel } \\
\cline { 2 - 5 } & \multicolumn{1}{c}{$\mathbf{Z A}$} & $\mathbf{Z N H}_{\mathbf{4}} \mathbf{C l}$ & $\mathbf{Z N H}_{\mathbf{4}} \mathbf{N O}_{\mathbf{3}}$ & $\mathbf{Z N H}_{\mathbf{4}} \mathbf{F}$ \\
\hline $\mathbf{S i}$ & 24,55 & 39,07 & 38,90 & 40,25 \\
$\mathbf{A l}$ & 4,07 & 2,51 & 3,22 & 2,92 \\
$\mathbf{C a}$ & 13,26 & 0,151 & 0,159 & 0,197 \\
$\mathbf{F e}$ & 4,02 & 0,0683 & 0,0758 & 0,0808 \\
$\mathbf{M g}$ & 2,52 & 0,0105 & 0,01 & 0,0124 \\
$\mathbf{N a}$ & 2,53 & 0,182 & 0,223 & 0,311 \\
$\mathbf{K}$ & 1,32 & 1,36 & 1,39 & 1,57 \\
$\mathbf{C u}$ & 0,913 & - & - & \\
$\mathbf{M n}$ & 0,137 & 0,0035 & 0,0039 & 0,0036 \\
$\mathbf{P b}$ & 0,109 & - & - & - \\
$\mathbf{T i}$ & 0,124 & 0,175 & 0,165 & 0,208 \\
$\mathbf{Z n}$ & 0,0715 & - & - & - \\
$\mathbf{C s}$ & 0,44 & - & - & - \\
$\mathbf{Z r}$ & - & 0,0251 & 0,0247 & 0,0278 \\
\hline
\end{tabular}

Keterangan : ZA (Zeolit Alam), $\mathrm{ZNH}_{4} \mathrm{Cl}$ (ZeolitAmmonium Klorida), $\mathrm{ZNH}_{4} \mathrm{NO}_{3}$ (Zeolit-Ammonium Nitrat), $\mathrm{ZNH}_{4} \mathrm{~F}$ (Zeolit-Ammonium Florida)

Tabel 1 menunjukkan bahwa proses aktivasi dengan aktivator garam amonium menyebabkan terjadinya pengurangan kadar logam $\mathrm{Na}$ secara signifikan, penambahan garam amonium menyebabkan terjadinya pertukaran ion $\mathrm{Na}^{+}$ dengan ion amonium sehingga menambah situssitus asam pada zeolit melalui mekanisme pertukaran ion tersebut. Berdasarkan Tabel 1, kadar $\mathrm{Na}^{+}$yang mengalami pengurangan terbesar terjadi pada zeolit teraktivasi amonium klorida $\left(\mathrm{ZNH}_{4} \mathrm{Cl}\right)$ sebesar $92,8 \%$ diikuti dengan amonium nitrat $\left(\mathrm{ZNH}_{4} \mathrm{NO}_{3}\right)$ sebesar $91 \%$ dan amonium florida $\left(\mathrm{ZNH}_{4} \mathrm{~F}\right)$ sebesar $87,7 \%$. Hal ini menunjukkan bahwa terjadi pertukaran ion 


\section{Verry Andre Fabiani dkk./ Indo. J. Chem. Res., 2017, 5(1), 1-6}

$\mathrm{Na}^{+}$dan ion amonium dalam jumlah besar pada zeolit dengan aktivator amonium klorida.

Gambar 2 menunjukkan bahwa rasio $\mathrm{Si} / \mathrm{Al}$ yang paling tinggi ditunjukkan oleh zeolit yang diaktivasi oleh garam amonium klorida yaitu sebesar 15,56. Tingginya rasio $\mathrm{Si} / \mathrm{Al}$ tersebut berkaitan dengan berkurangnya kadar logam $\mathrm{Na}$, $\mathrm{Ca}, \mathrm{Mg}$, Fe, dan K. Penambahan amonium klorida ini selain menyebabkan terjadinya pertukaran ion $\mathrm{Na}^{+}$dengan ion amonium juga terjadi pertukaran ion khususnya logam yang mudah membentuk garam klorida. Komponen yang mungkin larut dalam pertukaran ion ini adalah $\mathrm{Mg}, \mathrm{Ca}, \mathrm{K}, \mathrm{Na}$ dan Fe. Dengan demikian, rasio $\mathrm{Si} / \mathrm{Al}$ pada zeolit akan meningkat.

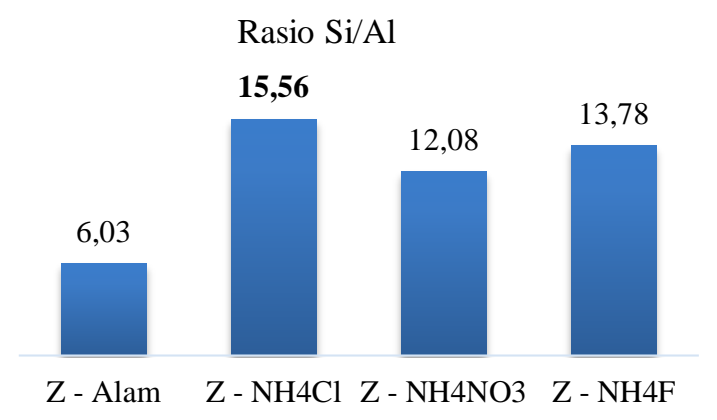

Gambar 2. Pengaruh aktivasi garam ammonium terhadap rasio $\mathrm{Si} / \mathrm{Al}$ pada zeolit alam

Perbandingan Si/Al mempengaruhi aktivitas katalis, semakin tinggi rasio $\mathrm{Si} / \mathrm{Al}$ maka semakin tinggi stabilitas termal dan kekuatan asam serta diperoleh sifat asam yang lebih besar dari semula. Modifikasi zeolit alam dengan variasi garam ammonium berhasil meningkatkan rasio $\mathrm{Si} / \mathrm{Al}$ zeolit alam dari 6,03 menjadi > 10. Zeolit dengan perbandingan Si dan Al yang tinggi (10100) dapat menyerap molekul non polar sehingga baik digunakan sebagai katalis asam dalam reaksi perengkahan hidrokarbon (Sutarti dan Rahmawati, 1994 ; Handhoyo dkk., 2005).

\section{Karakteristik Fisik Produk Perengkahan Minyak Jelantah}

Sifat fisik produk perengkahan yang diuji meliputi indeks bias, densitas dan viskositas kinematik. Hasil pengukuran sifat fisik produk perengkahan hasil penelitian ditunjukkan pada Tabel 2. Berdasarkan uji produk perengkahan yang dilakukan menunjukkan bahwa karakteristik viskositas kinematik ketiga produk perengkahan telah memenuhi nilai standar ASTM D975 untuk bahan bakar solar standar.
Nilai karakteristik densitas berada dibawah nilai standar SNI yaitu berkisar antara $0,76-0,77 \mathrm{~g} / \mathrm{mL}$ dimana produk yang memiliki densitas terbesar yaitu produk perengkahan $\mathrm{Z}-\mathrm{NH}_{4} \mathrm{Cl}$, rendahnya densitas ini menunjukkan bahwa pemisahan produk perengkahan masih belum optimal.

Tabel 2. Karakteristik Produk Perengkahan

Minyak Jelantah yang dibandingkan dengan Karakteristik Solar Standar

\begin{tabular}{|c|c|c|c|c|}
\hline \multirow{2}{*}{ Parameter } & \multirow{2}{*}{$\begin{array}{c}\text { Solar } \\
\text { Standar }\end{array}$} & \multicolumn{3}{|c|}{ Produk Perengkahan } \\
\hline & & $\mathrm{ZNH}_{4} \mathrm{Cl}$ & $\mathrm{ZNH}_{4} \mathbf{N O}_{3}$ & $\mathrm{ZNH}_{4} \mathbf{F}$ \\
\hline Indeks Bias & $1,3-1,45$ & $\begin{array}{c}1,431 \\
\left(32,3^{\circ} \mathrm{C}\right)\end{array}$ & $\begin{array}{c}1,429 \\
\left(32,3^{\circ} \mathrm{C}\right)\end{array}$ & $\begin{array}{c}1,435 \\
\left(32,3^{\circ} \mathrm{C}\right)\end{array}$ \\
\hline $\begin{array}{c}\text { Densitas } \\
(\mathrm{g} / \mathrm{mL}) \\
(\mathrm{SNI})\end{array}$ & $\begin{array}{l}0,82-0,87 \\
\left(40^{\circ} \mathrm{C}\right)\end{array}$ & $\begin{array}{c}0,77 \\
(32,3 \\
\left.{ }^{\circ} \mathrm{C}\right)\end{array}$ & $\begin{array}{c}0,76 \\
\left(32,3^{\circ} \mathrm{C}\right)\end{array}$ & $\begin{array}{c}0,76 \\
(32,3 \\
\left.{ }^{\circ} \mathrm{C}\right)\end{array}$ \\
\hline $\begin{array}{c}\text { Viskositas } \\
\text { kinematik } \\
\text { (cSt) } \\
\text { (ASTM } \\
\text { D975) }\end{array}$ & $\begin{array}{c}1,9-4,0 \\
\left(40^{\circ} \mathrm{C}\right)\end{array}$ & $\begin{array}{c}1,9 \\
\left(40^{\circ} \mathrm{C}\right)\end{array}$ & $\begin{array}{c}1,9 \\
\left(40^{\circ} \mathrm{C}\right)\end{array}$ & $\begin{array}{c}1,9 \\
\left(40^{\circ} \mathrm{C}\right)\end{array}$ \\
\hline
\end{tabular}
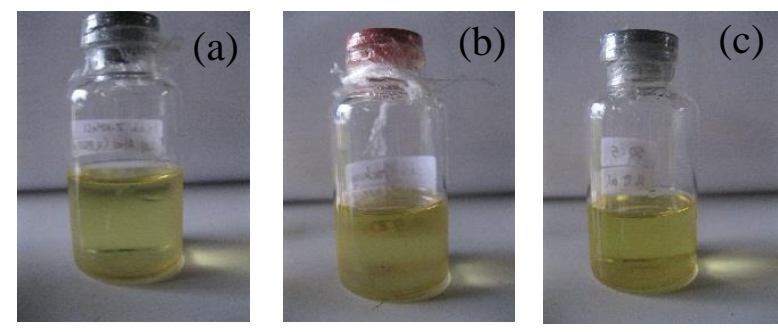

Gambar 3. Produk Perengkahan Minyak Jelantah

(a) $\mathrm{Z}-\mathrm{NH}_{4} \mathrm{Cl}$, (b) Z-NH $\mathrm{NO}_{3}$, (c) $\mathrm{Z}-\mathrm{NH}_{4} \mathrm{~F}$
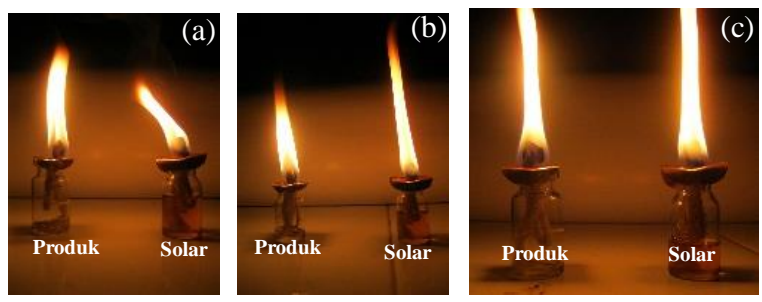

Gambar 4. Hasil uji nyala produk perengkahan yang dibandingkan dengan solar (a) $\mathrm{Z}-\mathrm{NH}_{4} \mathrm{Cl}$,

(b) $\mathrm{Z}-\mathrm{NH}_{4} \mathrm{NO}_{3}$, (c) Z- $\mathrm{NH}_{4} \mathrm{~F}$

Produk perengkahan (Gambar 3) yang dihasilkan memiliki warna kuning bening dan bau yang tajam. Tiap produk perengkahan kemudian dilakukan uji nyala api. Uji nyala api dilakukan dengan membandingkan nyala api yang dihasilkan produk perengkahan minyak jelantah dengan nyala api yang dihasilkan oleh solar. Hasil uji nyala api pada masing-masing produk ditunjukkan pada Gambar 4. 


\section{Verry Andre Fabiani dkk./ Indo. J. Chem. Res., 2017, 5(1), 1-6}

Hasil uji nyala pada Gambar 4 menunjukkan bahwa hasil pembakaran produk perengkahan pada masing-masing produk menghasilkan sedikit asap dibandingkan nyala api yang dihasilkan solar. Walaupun nyala api tiap produk berbeda, namun secara tampak fisik hasil dari uji pembakaran ini hampir sama. Pembakaran solar menghasilkan asap yang lebih banyak dan berwarna hitam, hal ini membuktikan bahwa produk perengkahan minyak jelantah menghasilkan pembakaran yang sempurna dan emisi gas yang dihasilkan lebih kecil dibandingkan dengan emisi gas yang dihasilkan oleh solar.

\section{KESIMPULAN}

Aktivator garam ammonium berhasil meningkatkan keasaman zeolit alam dari rasio $\mathrm{Si} / \mathrm{Al}$ 6,03 menjadi $>10$ (Rasio Si/Al $\mathrm{ZNH}_{4} \mathrm{Cl}=$ 15,$\left.56 ; \mathrm{ZNH}_{4} \mathrm{NO}_{3}=12,08 ; \mathrm{ZNH}_{4} \mathrm{~F}=13,78\right)$. Hal ini menunjukkan bahwa pengaruh garam ammonium terhadap keasaman zeolit alam sangat besar sehingga dapat digunakan sebagai katalis asam dalam reaksi perengkahan minyak jelantah.

\section{DAFTAR PUSTAKA}

Handhoyo, R, Herry P., Siti S., Iis N., Nita Y., Amelia, Ratna K., 2005, Peningkatan Rasio Si/Al Zeolit Alam Modernit sebagai Bahan Dasar Zeolit Katalis, J. Zeolit Indonesia. 4 : 19-23.

Ismail, Hanudin, E., 2005, Degradasi Mineral Batuan Oleh Asam-Asam Organik, J. Ilm. Tan. Ling., 5(1):1-17

Jestyssa, A.H , Maygasari, D.A., 2010. Optimasi Proses Aktivasi Katalis Zeolit Alam dengan Uji Proses Dehidrasi Etanol, Skripsi: Jurusan Teknik Kimia. Fakultas Teknik. Universitas Diponegoro Semarang.

Li, L., Zhiyong, D., Kun, L., Junming, X., Fusheng, L., Shiwei, L., Shitao, Y., Congxia, X., Xiaoping, G., 2015. Liquid hydrocarbon fuels from catalytic cracking of waste cooking oils using ultrastable zeolite USY as catalyst, J. Anal. Appl. Pyrol. Article in press.

Muller, J. M., 2014, Solid-State Dealumination of Zeolites for Use as Catalysts in Alcohol, Microporous and Mesoporous Materials. 204 : 50-57.
Park, S., Turgren, B., Wang, Y., Toshiki, N., Junko, N.K., Toshiyuki, Y., 2017, Acidic and catalytic properties of ZSM-5 zeolites with different Al distributions, Catal. Today. Accepted Manuscript.

Ramasamy, K.K., Zhang, H., Junming, S., Yong, W., 2014, Conversion of ethanol to hydrocarbons on hierarchical HZSM-5 zeolites, Catal. Today. Article in press

Rival, Harrizul, 1995, Asas Pemeriksaan Kimia. UI Press. Jakarta.

Saiapina, O.Y., Dzyadevych, S.V., Walcarius, A., Jafrrezic-Renault, N., 2012, A Novel Highly Sensitive Zeolite-Based Conductometric Microsensor for Ammonium Determination, Analytical Letters, 45: 1467-1484.

Silalahi I.H., Sianipar A. Sayekti E., 2011, Modifikasi Zeolit Alam menjadi Material Katalis Perengkahan, Jurnal Kimia Mulawarman, $8: 89-93$.

Song, C., Wang, M., Zhao, L., Nianhua, X., Luming, P., Xuefeng, G., Weiping, D., Weimin, Y., Zaiku, X., 2013, Synergism between the Lewis and Brönsted acid sites on HZSM-5 zeolites in the conversion of methylcyclohexane, Chin. J. Catal., 34 : 2153-2159.

Sutarti, M., dan Minta Rahmawati, 1994, Zeolit: Tinjauan Literature, Pusat Dokumentasi dan Informasi Ilmiah. Jakarta.

Tarach, K., Gora-Marek, K., Tekla, J., Brylewska, K., Datka, J., Mlekodaj, K., Makowski, W., Igualada Lopez, M.C., Martinez Triguero, J., Rey, F., 2014, Catalytic cracking performance of alkalinetreated zeolite Beta in the terms of acid sites properties and their accessibility, J. Catal. 312, 46e 57.

Tatsumi, Takashi, 2004, Zeolites: Catalysis, Encyclopedia of Supramolecular Chemistry, 1, 1610-1616, Yokohama National University, Yokohama, Japan

Triwahyuni, E., 2003, Types and Distribution of The Iron Species Formed in The Zeolite Structure, 7th Eurasia Chemical Conference. Karachi. Pakistan

Xu, W., Li, L. Y. \& Grace, J. R., 2014, Dealumination of Clinoptilolite and Its Effect on Zinc Removal from Acid Rock Drainage, Chemosphere. $111:$ 427-433. 